\title{
Synthesis of Chitosan from Prawn Shells and Characterization of its Structural and Antimicrobial Properties
}

\author{
Shanta Pokhrel, ${ }^{1,2}$, Ralf Lach ${ }^{3}$, Wolfgang Grellmann ${ }^{3}$, Andre Wutzler ${ }^{3}$, Werner Lebek ${ }^{4}$, Reinhold Godehardt ${ }^{4}$, Paras Nath \\ Yadav $^{1 \text {, }}$ \& Rameshwar Adhikari ${ }^{1,4,5 *}$ \\ ${ }^{1}$ Central Department of Chemistry, Tribhuvan University, Kirtipur, Kathmandu, Nepal \\ ${ }^{2}$ Department of Chemistry, Tri-Chandra Multiple Campus, Ghantaghar, Kathmandu, Nepal \\ ${ }^{3}$ Polymer Service GmbH Merseburg, Eberhard-Leibnitz-Straße 2, 06217 Merseburg, Germany \\ ${ }^{4}$ Institute of Physics, Martin Luther University Halle-Wittenberg, D-06099 Halle/Saale, Germany \\ ${ }^{5}$ Research Centre for Applied Science and Technology (RECAST), Tribhuvan University, Kirtipur, Kathmandu, Nepal
}

\section{KEYWORDS}

Antimicrobial screening; Chitosan; degree of deacetylation; FTIR spectroscopy; scanning electron microscopy

\section{"CORRESPONDENCE}

Tel: +977 1 4332034, Fax: + 97714330537

E-mail: paras_yadav2002@yahoo.com; nepalpolymer@yahoo.com

\section{ARTICLE History}

Received 07 June 2016

Revised 03 July 2016

Accepted 12 July 2016

\section{ACADEMic Editor}

Gan B. Bajracharya

\section{Abstract}

Chitin was prepared from prawn shells waste by chemical treatments viz. demineralization, deproteinization and decolorization. Chitosan was prepared by deacetylation of chitin with $50 \% \mathrm{NaOH}$ at $100{ }^{\circ} \mathrm{C}$ in the presence of nitrogen. Deacetylation was performed at different intervals of time to get a series of chitosans having different degrees of deacetylation. Prepared chitosans were characterized by molecularweight determination, degree ofdeacetylation, Fourier transform infrared (FTIR) spectroscopy and Scanning electron micrography (SEM). The degree of deacetylation of chitosans was calculated by acid base titration and potentiometric titration. The molecular weights of commercial and prepared chitosan (CS-4.0) samples were determined using the MarkHouwink equation and were found to be $3.5 \times 10^{5}(\mathrm{~g} / \mathrm{mole})$ and $3.3 \times 10^{4}(\mathrm{~g} / \mathrm{mole})$, respectively. The degree of deacetylation was found to linearly increase with the increase of reaction time. FTIR spectra showed the characteristic peaks of chitin and chitosan. Antimicrobial screening results revealed that the prepared chitosan (CS-4.0) was equally or more biologically active than the commercial chitosan.

\section{Introduction}

Chitin is a biopolymer, which is extracted from the exoskeletons of crustaceans, insects, molluscs and the cell wall of microorganisms (Muzzarelli 1997). It is widely distributed in terrestrial crustaceans, marine invertebrates, insects, silkworms, honeybees, mushrooms, fungi and yeast. Some common sources of chitin are shown in Fig. 1.

Chitin is the second most abundant biopolymer after cellulose found in nature (Muzzarelli 1997). Chitin is structurally similar to cellulose but it contains acetamide group instead of hydroxyl group $(-\mathrm{OH})$ at the $\mathrm{C}(2)$ in cellulose (Raafat and Sahl 2009; Dutta et al. 2004).

Chitin in crustacean shells is tightly associated with inorganic salts such as calcium carbonate, proteins and lipids, including pigments. There are two methods for the production of chitin and chitosan (Sekwon 2010): (i) First one is chemical method involving three steps of demineralization (DM), deproteinization (DP) and deacetylation (DA)

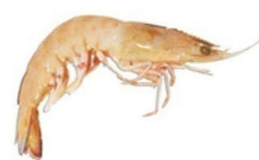

Prawn

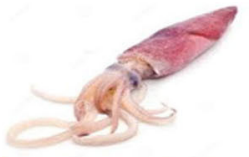

Squid processes (No and Lee 1995), and (ii) Second one is biological method involving fermentation process which is carried out using different bacteria (Jung et al. 2007, Jo et al. 2008). In this study, we prepared chitin by chemical method.

Chitosan is the alkaline deacetylated derivative of chitin, which is chemically defined as a copolymer of 2-acetamido2-deoxy-D-glucopyranose joined by $(1,4)$ glycosidic bonds (Dhawade et al. 2012; Pinho et al. 2009). Chitosan has a wide application in various fields such as biomedical (Yadav and Bhise 2004), food (No et al. 2007), textile (Ramchandran et al. 2004), waste water treatment (Aly et al. 1997; Ravi Kumar 2000), etc.

Materials like cellulose, chitin and collagen are used by the nature for different purposes such as to provide the structure of plants, as the exoskeleton of several insects and mollusca, and for the mechanical support in connective tissues (Pighinelli et al. 2013). A number of research works have been devoted

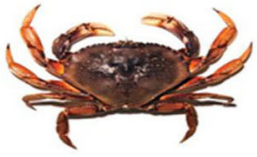

Crab

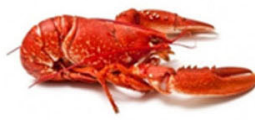

Lobster

Fig. 1. Some sources of chitin. 
out in the field of chitosan due to its good biocompatibility, biodegradation and various biofunctionalities such as homeostatic, immunity enhancing and wound healing properties (Zhang et al. 2001).

\section{Materials and Methods}

\subsection{Materials}

Hydrochloric acid, glacial acetic acid, sodium hydroxide, sodium hypochlorite and methyl orange indicator of analytical grade were obtained from Fisher Scientific, India and were used without further purification.

Crab shells' based commercial chitosan (FLUKA-48165) having degree of deacetylation of $77.8 \%$ was purchased from Sigma Aldrich, Germany.

For the antimicrobial screening, three strains of Gram negative bacteria (Escherichia coli ATCC 25922, Klebsiella pneumoniae ATCC 700603 and Salmonella typhimurium ATCC 14028) and two strains of Gram positive bacterium (Staphylococcus aureus ATCC 25923 and Enterococcus faecalis ATCC 29512) were used. All the strains were obtained from National Public Health Laboratory, Teku, Kathmandu, Nepal and maintained at Central Department of Biotechnology, Tribhuvan University, Kathmandu, Nepal.

\subsection{Preparation of chitosan}

\subsubsection{Extraction of chitin from prawn shells}

Prawn shells' powder of $\leq 0.425 \mathrm{~mm}$ average grain diameter was prepared by washing, drying, grinding and sieving. Chitin was isolated from prawn shells by chemical processes viz. demineralization, deproteinization and decolorization (No and Lee 1995).

Demineralization (DM) Prawn shells' powder (227.3 g) was treated with $1 \mathrm{M} \mathrm{HCl}$ in a 1:15 weight/volume ratio. The reaction was carried out for $2 \mathrm{~h}$ at room temperature. Obtained solid was washed until the neutrality was reached. Yield: $20.96 \%$.

Deproteinization (DP) Demineralized powder (47.6 g) was treated with $150 \mathrm{~g} / \mathrm{l}$ of $\mathrm{NaOH}$ solution in 1:10 weight/volume ratio. The mixture was heated at $65^{\circ} \mathrm{C}$ for $3 \mathrm{~h}$ in a reaction flask. Obtained chitin was washed with water until neutrality was reached and dried in oven at $40^{\circ} \mathrm{C}$. Yield: $63.21 \%$.

Decolorization (DC) Chitin (30 g) was then decolorized by $2 \%$ sodium hypochlorite solution $(600 \mathrm{~mL})$ in 1:20 ratio of chitin and NaClO. The mixture was stirred for $30 \mathrm{~min}$ at $45^{\circ} \mathrm{C}$. Obtained chitin was washed until the neutrality was reached. Yield: $81.4 \%$.

\subsubsection{Deacetylation (DA) of chitin}

Chitin was treated with sodium hydroxide (50\% solution) in a 1:10 weight/volume ratio. The reaction was carried out at $100{ }^{\circ} \mathrm{C}$ for different intervals of time $(0.5,1,2$ and $4 \mathrm{~h})$ in nitrogen atmosphere (Scheme 1) (Pokhrel et al. 2015). To yield a higher viscosity and molecular weight distributions, inert atmospheric conditions of nitrogen was important since substantial degradation effect on chitosan had occurred when deacetylation was carried out in the presence of oxygen (Sekwon 2010). The residue was then separated, cooled and

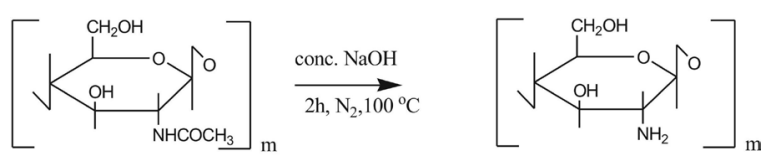

Scheme 1. Schematic representation of deacetylation of chitin to chitosan. washed with water until to the neutral $\mathrm{pH}$.

\subsection{Characterization of chitosan}

\subsubsection{Measurement of degree of deacetylation}

Degree of deacetylation of the prepared chitosan was measured by acid-base titration and potentiometric titration.

Acid-base titration Chitosan ( $0.3 \mathrm{~g}$ ) was dissolved in $30 \mathrm{ml}$ of 0.1 $\mathrm{M} \mathrm{HCl}$, stirred for $20 \mathrm{~min}$ at room temperature and titrated against $0.1 \mathrm{M} \mathrm{NaOH}$ solution in the presence of methyl orange indicator. The percentage of moisture content was measured by gravimetric method (Sekwon 2010) and the percent of free $\mathrm{NH} 2$ groups in chitosan was calculated as follows (Yuan et al. 2011):

$$
\begin{gathered}
\mathrm{NH}_{2} \text { content }=\frac{\left(\mathrm{C}_{1} \mathrm{~V}_{1}-\mathrm{C}_{2} \mathrm{~V}_{2}\right) \times 0.016}{\mathrm{G}(100-\mathrm{W})} \times 100 \\
\text { Free } \mathrm{NH}_{2} \%=\frac{\mathrm{NH}_{2} \%}{9.94 \%} \times 100 \%
\end{gathered}
$$

where, $\mathrm{C}_{1}=$ concentration of $\mathrm{HCl}(\mathrm{M}), \mathrm{C}_{2}=$ concentration of $\mathrm{NaOH}(\mathrm{M}), \mathrm{V}_{1}=$ volume of $\mathrm{HCl}$ added $(\mathrm{ml}), \mathrm{V}_{2}$ $=$ volume of $\mathrm{NaOH}$ added by titration $(\mathrm{ml}), \mathrm{G} \stackrel{2}{=}$ sample weight (g), W = weight of moisture content.

Potentiometric titration Chitosan $(0.5 \mathrm{~g})$ was dissolved in 20 $\mathrm{ml}$ of $0.3 \mathrm{M} \mathrm{HCl}$ and distilled water $(400 \mathrm{ml})$ was added to dilute it. This solution was titrated with a $1 \mathrm{M} \mathrm{NaOH}$ solution. A titration curve of potential versus $\mathrm{NaOH}$ titration volume was generated. The curve's inflection points were found for each indicated transition. The volume of $\mathrm{NaOH}$ at each inflection point was applied to the equation (Yuan et al. 2011):

$\mathrm{NH}_{2} \%=16.1 \times(\mathrm{y}-\mathrm{x}) / \mathrm{M}$

where, $M$ is the weight of chitosan used, $x$ is the first inflection point on the graph of potential versus titration volume and $y$ is the second inflection point.

\subsubsection{Viscosity average molecular weight determination}

Viscosity average molecular weight was determined by viscometric measurement by Ostwald's viscometer. The intrinsic viscosity of the prepared sample was determined from the Huggins equation (Lapasin and Pricl 1999):

$$
\frac{n_{s p}}{c}=n+k n^{2}
$$

where, nsp is specific viscosity calculated from the solution and solvent flow time ratio, $\mathrm{n}$ is intrinsic viscosity, $\mathrm{c}$ is chitosan concentration in the solution and $\mathrm{k}$ is a constant.

From the intrinsic viscosity, the molecular weight was determined by employing the MarkHouwink equation (Lapasin and Pricl 1999): [n] = $\mathrm{kM}^{\alpha}$,where, $\mathrm{M}$ is viscosity average molecular weight; $\mathrm{K}$ and are constants, whose values depend on the polymer type and the chosen solvent. These constants $\mathrm{k}$ and $\alpha$ values for chitosan and the solvent $(0.2 \mathrm{M}$ sodium acetate and $0.3 \mathrm{M}$ acetic acid buffer) are $8.2 \times 10^{-32}$ and 0.76 , respectively.

\subsubsection{Spectroscopic and microscopic characterization}

The structural characterization of the polymers was carried out by Fourier transform infrared spectroscopy (Perkin Elmer FTIR-2000) in ATR mode. Morphological characterization was carried out by Scanning electron microscope (JSEM6300, JEOL) by secondary electron (SE) imaging mode. 
Table 1. List of chitosan samples with specimens' codes prepared with variation of deacetylation time as indicated

\begin{tabular}{llll}
\hline Sample code & $\begin{array}{l}\text { Reaction } \\
\text { time }(\mathrm{h})\end{array}$ & DD (\%) & DD (\%) \\
\hline CS-0.5 & 0.5 & 24.03 & 23.03 \\
CS-1.0 & 1.0 & 32.06 & 32.41 \\
CS-2.0 & 2.0 & 40.40 & 41.64 \\
CS-4.0 & 4.0 & 66.50 & 64.70 \\
\hline
\end{tabular}

Sample code CS-0.5, CS-1.0, CS-2.0, CS-4.0 refer to chitosan that obtained after deacetylation for $0.5,1,2$ and $4 \mathrm{~h}$ respectively. $\mathrm{DD}=$ Degree of deacetylation determined by a) Acid-base titration and

b) Potentiometric titration.

Table 2. Zones of inhibition (diameter in $\mathrm{mm}$ ) produced by the test compounds in the antibacterial screening

\begin{tabular}{llllll}
\hline Test compounds & $\begin{array}{l}\text { E. } \\
\text { coli }\end{array}$ & $\begin{array}{l}\text { K. } \\
\text { pneumoniae }\end{array}$ & $\begin{array}{l}\text { S. } \\
\text { typhimurium }\end{array}$ & $\begin{array}{l}\text { E. } \\
\text { faecalis }\end{array}$ & $\begin{array}{l}\text { S. } \\
\text { aureus }\end{array}$ \\
\hline CS-4.0 & 9 & 8 & 9 & 9 & 10 \\
CS-com & - & - & 10 & 8 & 8 \\
1\% Acetic acid & - & - & - & - & - \\
Chloramphenicol & 24 & 26 & 36 & 30 & 36 \\
\hline
\end{tabular}

\subsection{Antibacterial screening}

Antibacterial screening was done by Agar Well Diffusion Method (Sekwon 2010). In this method, chitosan solutions $(20 \mu \mathrm{l})$ were placed on equal sized wells $(4.0 \mathrm{~mm})$ bored on the preset agar plates along with the positive (Chloramphenicol, $50 \mu \mathrm{g} / \mathrm{disc}$ ) and negative ( $1 \%$ acetic acid, $20 \mu \mathrm{l}$ ) controls. Then the zone of inhibition observed as halozones was measured. The diameter of this clear zone shows the antibacterial efficacy of the compound tested. All the samples of chitosan were dissolved in $1 \%$ acetic acid at a concentration of $12.5 \mathrm{mg} / \mathrm{ml}$.

\section{Results and Discussion}

Chitosan was successfully prepared from prawn shells and physicochemical properties were determined (measuring of degree of deacetylation by acid-base and potentiometer titrations, and average viscosity molecular weight by viscometric method). The chitin and chitosan were characterized by FTIR spectroscopy and SEM. The degree of deacetylation is presented in Table 1 , which is the correlation between acid-base titration and potentiometric titration methods. It was observed that the degree of deacetylation of chitosan linearly increased with the increase of reaction time.

The molecular weight of commercial chitosan was $3.5 \times 10^{5}(\mathrm{~g} / \mathrm{mole})$ whereas that of representative prepared chitosan (CS-4.0) was found $3.3 \times 10^{4}(\mathrm{~g} / \mathrm{mole})$ respectively. Thus the molecular weight of commercial chitosan was observed higher than the sample synthesized in this study. The molecular weight of chitosan depends on various factors such as conditions for deacetylation process, chitin sources, concentration of alkali, duration of deacetylation, methods of demineralization, particles size, etc (Tajik et al. 2008).

Fig. 2 shows the FTIR spectra of chitin, synthesized chitosan (CS-4.0) and commercial chitosan (CS-com). Chitosan exhibited characteristic peaks at $1633 \mathrm{~cm}^{-1}$ (amide $\mathrm{I}, \mathrm{C}=\mathrm{O}$ stretching) and $1559 \mathrm{~cm}^{-1}$ (amide II, $\mathrm{N}-\mathrm{H}$ bending) due to its amide groups (Czechowska-Biskup et al. 2012). The $\mathrm{N}-\mathrm{H}$ and $\mathrm{O}-\mathrm{H}$ stretchings $\left(3455 \mathrm{~cm}^{-1}\right), \mathrm{C}-\mathrm{H}$ stretching $(2889$ $\mathrm{cm}^{-1}$ ) and $\mathrm{C}-\mathrm{O}-\mathrm{C}$ stretching peak $\left(1022 \mathrm{~cm}^{-1}\right)$ were the characteristic peaks of chitin and chitosan (Peng et al. 2009). The band at $1320 \mathrm{~cm}^{-1}$ in the FTIR spectra of chitin as well as in the prepared chitosan (CS-4.0) was assigned to complex vibrations due NHCO group (amide III band), which was absent in the spectra of commercial chitosan due to difference in degree of deacetylation (CzechowskaBiskup et al. 2012). Comparison of the FTIR spectra of both synthesized and commercial chitosan revealed the conversion of chitin to chitosan after deacetylation. The $-\mathrm{OH}$ and $-\mathrm{NH}$ stretching bands were found to overlap resulting in the broadening of the peak, which indicated the presence of hydrogen bonding between $-\mathrm{NH}$ and $-\mathrm{OH}$ groups. The peaks at $1633 \mathrm{~cm}^{-1}$ (for-CONHR group) and $1544 \mathrm{~cm}^{-1}$ (amine $-\mathrm{NH} 2$ ) were also observed (Czechowska-Biskup et al. 2012).

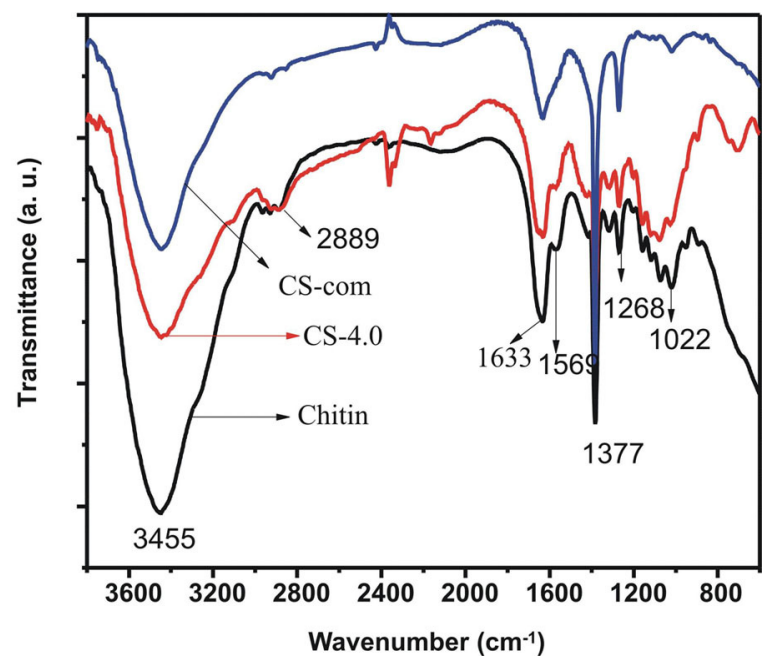

Fig. 2. FTIR spectra of chitin, synthesized chitosan (CS-4.0) and commercial chitosan (CS-com).

The SEM of chitin, commercial chitosan (CS-com) and prepared chitosan (CS-4.0) are presented in Fig. 3. Chitin powder under SEM revealed the typical cellular structures of the animal skeleton. Commercial chitosan (CS-com) sample showed the flakes-like structures and synthesized chitosan (CS-4.0) showed more or less flakes like structures.

The synthesized chitosan (CS-4.0) showed antimicrobial activity against both types of Gram positive as well as Gram negative bacteria i.e. E. coli, K. pneumoniae, S. typhimurium, E. faecalis and S. aureus, whereas commercial chitosan (CS-com) was found to inhibit $S$. typhimurium, E. faecalis and $S$. aureus (Table 2). Therefore, synthesized chitosan (CS-4.0) was found more effective than the commercial one with regard to the antimicrobial activity.

The antimicrobial activity of the chitosan is affected by different factors such as viscosity, molecular weight (Liu et al. 2006; Senel and McClure 2004), degree of polymerization (Ralston et al. 1964; Uchida et al. 1989) and degree of deacetylation (Sekiguchi et al.1994). Molecular weight and viscosity of the chitosan affect the diffusion of samples in Mueller Hinton Agar media in the antimicrobial activity assay. The molecular weight and viscosity of commercial chitosan (CS-com) was higher than that of synthesized chitosan (CS-4.0) in our study. It could be a reason for showing better antimicrobial activity by the synthesized chitosan which is also supported by the results of Liu et al. (2006) and Senel and McClure (2004). They have mentioned that chitosan with lower molecular weight showed greater antimicrobial activity.

\section{Conclusion}

Chitin was successfully isolated from prawn shells and chitosan was synthesized from chitin by deacetylation 

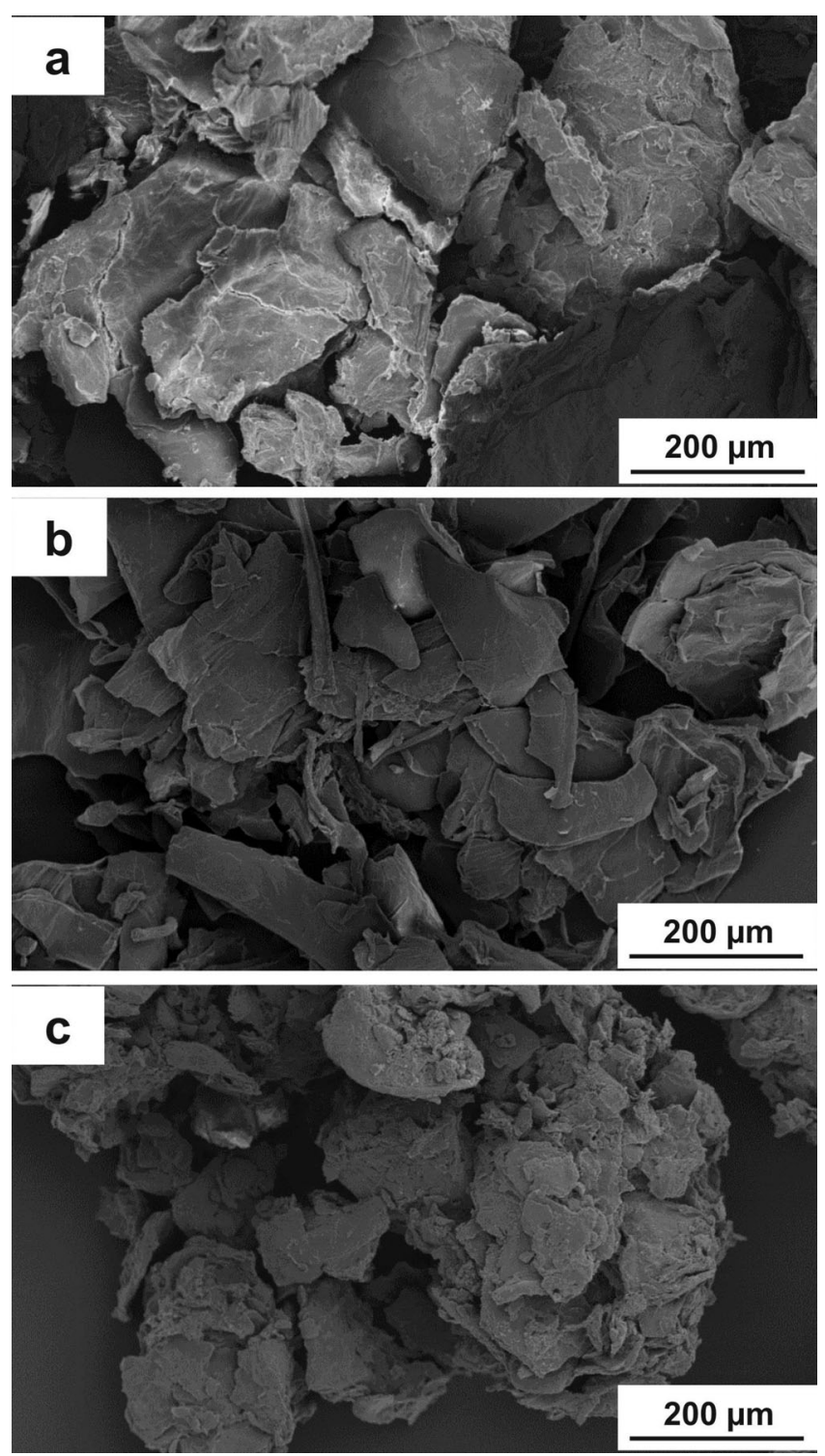

Fig. 3. SEM micrographs: (a) chitin, (b) commercial chitosan (CS-com) and (c) chitosan (CS-4.0) synthesized in this work.

process. Chitosans with different degree of deacetylation were obtained with the variation of treatment time with $50 \%$ $\mathrm{NaOH}$. It was found that the degree of deacetylation increased linearly with the increase of reaction time. The molecular weight of the commercial chitosan was observed higher than the synthesized chitosan. FTIR spectra of chitosan suggested that the formation of chitosan from chitin. SEM of chitin powder revealed the typical cellular structures of the animal skeleton. Commercial chitosan sample showed the flakeslike structures and synthesized chitosan showed more or less flakes like structures. Synthesized chitosan exhibited effective antibacterial activity.

Acknowledgements We would like to acknowledge Nepal Academy of Science Technology (NAST), Lalitpur, Nepal for providing Ph. D. fellowship grant to S. Pokhrel. German Research Foundation (DFG) and Alexander von Humboldt Foundation are acknowledged for research stay of SP and RA at Merseburg and Halle. We are grateful to Dr. Rajani Malla, Head, Central Department of Biotechnology, Tribhuvan University for providing laboratory facilities to conduct antimicrobial tests.

\section{References}

Aly, Y., B. evaluation of chitin derivatives for waste water treatment. Journal of Applied Science 65:1939-1946.

Czechowska-Biskup, R., D. Jarosinska, B. Rokita, P. Ulanlki, and J.M. Rosiak. 2012. Determination of degree of deacetylation of chitosan comparison methods. Progress on Chemistry and Application of Chitin and Its Derivatives 17:5-20.

Dhawade, P. P., and R. N. Jagtap. 2012. Characterization of the glass transition temperature of chitosan and its oligomers by temperature modulated differential scanning calorimetry. Advances in Applied Science Research 3(3):1372-1382.

Dutta, P. K., J. Dutta, and V. S. Tripathi. 2004. Chitin and chitosan: chemistry, properties and applications. Journal of Scientific and Industrial Research 63:20-31.

Jo, G. H., W. J. Jung, J. H. Kuk, K. T. Oh, Y. J. Kim, and R. D. Park. 2008. Screening of protease-producing Serratia marcescens FS-3 and its application to deproteinization of crab shell waste for chitin extraction. Carbohydrate Polymers 74:504-508.

Jung, W. J., G. H. Jo, J. H. Kuk, K. Y. Kim, and R.D. Park. 2007. Production of chitin from red crab shell waste by successive fermentation with Lactobacillus paracasei KCTC-3074 and Serratia marcescens FS-3. Carbohydrate Polymers 68:746-750.

Lapasin, R., and S. Pricl. 1999. Rheology of industrial polysaccharides: theory and applications. Aspen Publisher. Inc. Gaithersburg, Maryland.

Liu, N., X.G.Chen, H.J.Park, C.G. Liu, C.S. Liu, X.H.Meng, and L.J.Yu. 2006. EffectofMWandconcentration of chitosanonantimicrobial activity of Escherichia coli. Carbohydrate Polymers 64:60-65.

Muzzarelli, R. A. A. 1977. Chitin. Pergamon Press Ltd. Headington Hill Hall, Oxford, England.

No, H. K., and M. Y. Lee. 1995. Isolation of chitin from crab shell waste. Journal of Korean Society Food Nutrition 24:105-113.

No, H., S. Meyers, W. Priyankawiwatkul, and Z. Xu. 2007. Application of chitosan for improvement of quality and shelf life of foods. Food Science 72:R87-R100.

Peng, F., L. Rea, F. Xu, J. Bian, P. Peng, and R.C. Sun. 2009. Comparative study of hemicelluloses obtained by graded ethanol precipitation from sugarcane bagasse. Journal of Agriculture Food Chemistry 57:6305-6317.

Pighinelli, L., and M. Kucharska. 2013. Chitosan-hydroxyapatite composites. Carbohydrate Polymers 93:256-262.

Pinho, E. D., A. Martins, J. V. Araujo, R. L. Reis, and N. M. Neves. 2009. Degradable particulate composite reinforced with nanofibres for biomedical application. Acta Biomaterialica 5:1104-1114.

Pokhrel, S., P. N. Yadav, and R. Adhikari. 2015. Applications of chitin and chitosan in industry and medical sciences: a review. Nepal Journal of Science and Technology 16(1):99-104.

Raafat,D.,andH.G.Sahl.2009.Chitosananditsantimicrobialpotential -acriticalliterature survey. Microbialbiotechnology2(2):186-201.

Ralston, G. B., M. V. Tracey, and P. M. Wrench. 1964. The inhibition of fermentation in baker's yeast by chitosan. Biochimica and Biophysica Acta 93:652-655.

Ramchandran, T., K. Rajendra Kumar, and R. Rajendran. 2004. Antimicrobial textiles. Journal of the Institution of Engineers 84:42-47.

Ravi Kumar, M. N. V. 2000. A review of chitin and chitosan applications. Reactive and functional Polymer 46:1-27.

Sekiguchi, S., Y. Miura, H. Kaneko, S. I. Nishimura, N. Nishi, M. Iwase, and S. Tokura. 1994. Molecular weight dependency 
of antimicrobial activity by chitosan oligomers. Pages 7176 in K. Nishinari and E. Doi, editors. Food hydrocolloids: structures, properties and functions. Plenum Press, New York.

Sekwon, K. 2010. Chitin, chitosan, oligosaccharides and their derivatives: biological activities and applications. Pages 37-45 in G. H. Jo, R. D. Park and W. J. Jung, editors. Enzymatic production of chitin from crustacean shell waste. CRC Press, New York.

Senel, S., and S. J. McClure. 2004. Potential applications of chitosan in veterinary medicine. Advanced Drug Delivery Reviews 56:1467-1480.

Tajik, H., M. Moradi, S. M. R. Rohani, A. M. Erfani, and F. S. S. Jalali. 2008. Preparation of chitosan from brine shrimp (Artemia urmiana) cyst shells and effects of different chemical processing sequences on the physicochemical and functional properties of the product. Molecules 13:1263-1274.
Uchida, Y., M. Izume, A. Ohtakara. 1989. Preparation of chitosan oligomers with purified chitosanase and its application. Pages 373-382 in G. Skjak-Braek, T. Anthonsen and P. A. Sandford, editors. Chitin and chitosan: sources, chemistry, biochemistry, physical properties and applications. Elsevier Applied Science, London, U.K.

Yadav, A., and S. Bhise. 2004. Chitosan: a potential biomaterial effective against typhoid. Current Science 87:1176-1178.

Yuan, Y., B. M. Chesnutt, W. O. Haggard, and J. D. Bumgardner. 2011. Deacetylation of chitosan: material characterization and in vitro evaluation via albumin adsorption and pre-osteoblastic cell cultures. Materials 4:1399-1416.

Zhang, Y., and M. Zhang. 2001. Synthesis and characterization of macroporous chitosan/calcium phosphate composite scaffolds for tissue engineering. Journal of Biomedical Materials Research 55:304-312. 